\title{
Electronic and Student-created Dictionaries for Enhancing EFL Pronunciation and Vocabulary Usage
}

\author{
Hosam ElDeen Ahmed El-Sawy \\ Jouf University, KSA; \\ Damanhour University, Egypt
}

\begin{abstract}
The aim of this research is to investigate the effect of using electronic dictionaries combined with student-created dictionaries on English major students' pronunciation and vocabulary usage. Students' perceptions of this learning experience are also examined. The study combines both quantitative and qualitative research methodologies. Tests for pronunciation and vocabulary usage were designed and administered to73 English major students at Jouf University, KSA. Two questionnaires were designed to investigate students' perceptions. Results of the study revealed that the usage of electronic and student-created dictionaries improved students' pronunciation as well as their vocabulary usage abilities. Results also revealed that participants are willing to use both electronic and student-created dictionaries in vocabulary learning. The most frequent perceived benefits of electronic dictionaries are the speed of accessing the meaning of new vocabulary and getting clear correct pronunciation of them. The most frequent perceived benefits of studentcreated dictionaries are long retention and internalization of new vocabulary. Participants face some difficulties when using electronic dictionaries such as the inability to find accurate meaning of some vocabulary items and some technical problems. Participants face some difficulties with their student-created dictionaries such as difficulty in constructing illustrative sentences and time-consumption. The study recommends the incorporation of electronic and student-created dictionaries in vocabulary learning.
\end{abstract}

Index Terms-EFL, e-dictionaries, student-created, pronunciation, vocabulary

\section{INTRODUCTION}

The use of electronic dictionaries (e-dictionaries) in learning English has become widespread with the wide usage of smartphones all over the world. The use of e-dictionaries is very easy as the learner can get the meaning of the word as well as its correct pronunciation in no time. This use of e-dictionaries is one application of blended learning. Blended learning focuses on the idea that learning happens both through face-to-face interaction as well as through electronic means. The student-created dictionary refers to the dictionary every learner builds for himself through accumulating new words with their meanings day after day in a special notebook. The idea of student-created dictionaries is related to students' autonomy in language learning. The idea is that the learner not only gets the meaning of the new word from a dictionary but also writes it down in a special notebook together with an illustrative sentence from his creation. The learner writes the word, its meaning in his native language, a hint for its pronunciation, and puts it in a sentence that clarifies its meaning. This is very important for internalizing the new vocabulary and building an active vocabulary repertoire.

The study hypothesizes that the use of e-dictionaries combined with student-created dictionaries will enhance learners' pronunciation of new vocabulary items as well as their ability to use these items. The study also seeks to find out learners' perceptions of this learning experience. The study also expects that students will face a number of challenges during this learning experience. Studying these variables could enhance second language acquisition and learning processes.

The study starts with a comprehensive literature review followed by a full description of the methodology used. Results related to research questions are presented and analyzed. Discussion of these results and recommendations based on them are presented at the end.

\section{REVIEW OF LITERATURE}

\section{A. Effectiveness of Electronic Dictionaries}

A number of studies found out that the use of e-dictionaries is effective especially in the field of vocabulary learning. These studies include the following:

Bahri and Mahadi (2016) studied the use of Google Translate as a tool for aiding international students in Malaysia to develop their knowledge and skills in learning the Malay Language. Sixteen international students participated in the study. The majority of participants regarded Google Translate as an effective tool for learning vocabulary, as well as 
improving writing, and reading in the Malay Language.

Fageeh (2014) studied the effects of using online dictionaries on developing the skills of vocabulary building and enhancing positive attitudes of EFL learners towards vocabulary learning. The study employed a pretest posttest control group design combined with a qualitative questionnaire for investigating learners' attitudes. The study revealed that the use of online dictionaries has positive effects on improving the skills of vocabulary learning as well as enhancing learners' attitudes towards vocabulary learning.

Nisbet and Austin (2013) found out that Applications available for mobile phones are effective instruments for enhancing vocabulary learning among adult learners in programs of English as a second language.

Loucky (2010) reviewed the general findings about the alterations in use of electronic dictionaries by Japanese EFL university students. The researcher compared freshmen students' use and graduate students' use of e-dictionaries focusing on the degree of use. The researcher concluded that the use of e-dictionaries could enhance language learning. The researcher also focused on strategy training in effective use of e-dictionaries, which could enhance the positive effects of using these dictionaries. The researcher calls for more studies in the field of e-dictionaries focusing on raising students' awareness of the potentials of this type of dictionaries.

\section{B. Benefits of Electronic Dictionaries}

Studies found out that there are many benefits of the use of e-dictionaries in language learning. These benefits include: enhanced self-learning, easy access to written and spoken translations of a lot of languages, speed of use, enhancing recognition of word forms, enhancing recognition of word meanings, consolidation of word meanings, improving comprehension of reading passages, increasing incidental unconscious vocabulary acquisition, enhancing positive attitudes towards vocabulary learning, designing effective vocabulary lessons, achieving success in vocabulary tests, and learning vocabulary in authentic texts.

Bahri and Mahadi (2016) in their study of the use of Google Translate as a tool for helping international students in Malaysia to develop their knowledge and skills in learning the Malay Language found out that some participants reported that the effective use of Google Translated could enhance self-learning. consequently, the use of Google Translate for doing classroom tasks can help students study independently, and help them form their own strategies for solving problems that occur during language learning.

Nisbet and Austin (2013) indicated that Google Translate provides free text translation for 70 languages. They added that this app can change speech-to-text in 17 languages. Google translate provides the opportunity to listen to translations spoken in 40 languages. Besides, this app can spell the translation of non-Latin script languages like Chinese and Japanese in Latin letters that can be read easily. They added that Google Translate is the top-rated app for accuracy of translation.

Chen (2010) compared patterns of use and perceptions of pocket e-dictionaries and paper dictionaries. The researcher also investigated the impact of both types of dictionary use on vocabulary learning. The researcher found that there are no significant differences between e-dictionaries and paper dictionaries in comprehension, production and retention of vocabulary, however, e-dictionaries is significantly faster than paper dictionaries. Loucky (2002) who investigated the accessing speed of several kinds of e-dictionaries depending on both objective and subjective feedback from learners using them found similar results. The researcher found that both learners and language instructors were impressed by the wide potentials and speed of e-dictionaries, but they often needed more training in using them.

Dilenschneider (2018) investigated three conditions for language learners to learn new target words and comprehend a reading passage when using an online dictionary. The research questions concentrated on how each condition affected the recall and recognition of forms of words, meanings of words, and comprehension of the passage. The results revealed that the use of online dictionaries was helpful in the three aspects investigated. Similar result were found by Wang (2012) who focused on the pedagogical outcomes of using e-dictionaries by intermediate and advanced learners. In this study, twenty intermediate and advanced participants were asked to read an e-text twice with the help of an edictionary. After reading, participants wrote recalls of the text in English. The researcher found that intermediate students frequently looked up high, middle and low frequency words, while advanced students only looked up low frequency words. The study found out that e-dictionaries helped intermediate participants more than advanced participants in the field of consolidating meanings of already known words, learning new words and enhancing overall reading comprehension.

Abraham (2008) conducted a meta-analysis of 11 studies of the effect of electronic glosses on improving second language reading comprehension and enhancing incidental unconscious vocabulary learning. The researcher found out positive effects of electronic glosses on both reading comprehension and incidental unconscious vocabulary acquisition. The researcher recommended more studies in the field to verify the positive effects of electronic glosses in improving reading comprehension and vocabulary acquisition.

Fageeh (2014) as mentioned above reached the conclusion that e-dictionaries were beneficial for both improving vocabulary building skills and enhancing learners' positive attitudes towards learning vocabulary. Related to the positive perception of students of e-dictionaries is the study of Chiu and Liu (2013) who found out that e-dictionaries attract students' attention especially at the beginning of their use.

Loucky (2005) discussed the role of e-dictionaries in maximizing the steps of vocabulary learning including word knowledge, access of new meanings, storage of new information, analysis of word parts, placing new vocabulary items 
in short-term memory, linkage of new words to word groups, activating words for use, and recycling words. The researcher concluded that e-dictionaries could help create effective and enjoyable vocabulary lessons.

Niitemaa and Pietilä (2018) studied the relationship between Finnish EFL learners' ability to look up new words in online dictionaries and their success rate in vocabulary tests. The study focused on the correlation between the skills of looking words up in e-dictionaries and the skills of word recognition, which is one important aspect of success in vocabulary tests. The results of the study revealed that there was positive correlation between the skill of looking words up in e-dictionaries and their abilities in word recognition, which led to their success in vocabulary tests. However, this applied to individual words but not with collocations.

Dalton and Grisham (2011) investigated the value of using online dictionaries especially Google Translate in helping learners of English learn new vocabulary items. The researchers found out that online translation devices help learners acquire vocabulary as they appear naturally in authentic texts and allows learners to use the knowledge of their first language to enhance their understanding of new vocabulary items in the target language. However, the researchers emphasized that online dictionaries especially Google Translate are not completely accurate and they should be used as only a gateway for vocabulary learning.

\section{Learners' Attitudes towards Electronic Dictionaries}

Some studies found that learners have positive attitudes towards the use of e-dictionaries. For, example, Lenders (2008) found out that language learners think that e-dictionaries are appropriate and useful. The researcher discovered also that learners tend to use the e-dictionaries more when they can see the relationship between their use of these dictionaries and the enhancement of their studies and their future career. The researcher recommended that to be effective in vocabulary learning, the use of e-dictionaries should be accompanied by using authentic texts and tasks that require language use.

Moreover, Bower and McMillan (2007) found that the percentage of Japanese students' use of e-dictionaries is rising. The researcher found also that students feel that these dictionaries are helpful and they are keen on having them in their English classes. The researchers found that the percentage of students who use e-dictionaries at Kanda University reached $97 \%$ percent, which shows positive attitudes towards their use.

\section{Limitations of the Use of Electronic Dictionaries}

Researchers found out some limitations of the use of e-dictionaries. For example, e-dictionaries are not effective when used alone. In addition, they attract the attention of students' only at first use. Moreover, students do not know their useful functions and lack the experience in dealing with them. Besides, the overuse of e-dictionaries can make students lazy and hinder their ability to guess the meaning of unfamiliar words through the use of contextual clues. These limitations are highlighted in the following studies.

Poole (2012) conducted a study to compare the effectiveness of online glosses empowered with modified corpusextracted sentences and those enhanced with dictionary definitions taken from an online learner's dictionary for improving vocabulary learning. Participants in both groups showed gains in receptive and judgment tasks, but only the corpus-enhanced group showed improvement on the productive assessment. Moreover, the corpus-enhanced group indicated that the glosses were useful and likely to be used for future language study, while the dictionary group said that the glosses would not be used later as the annotations were perceived as ineffective. Therefore, this study revealed that the use of online dictionaries alone is not effective and special types of enhanced dictionaries are supposed to be used to achieve effective results.

Chiu and Liu (2013) compared the use of e-dictionaries with the use of printed dictionaries. The researchers found out that e-dictionaries attract students' attention at the beginning of use but they do not help students retain new vocabulary items as effective as printed dictionaries. Consequently, the researchers recommended that e-dictionaries should be used as a starter to attract students' attention and then they should be directed to use printed dictionaries to help them retain target vocabulary items with their meanings.

Bower and McMillan (2007) found out that many students in Canadian universities use e-dictionaries. However, they found that many of the users of e-dictionaries are unaware of numerous useful functions of these dictionaries such as the use of memory, history records, voice function, and recording students' own voice. Consequently, the limitation here is related to students' training in using electronic dictionaries. Kobayashi (2007) emphasized a similar limitation, which is the lack of experience in using e-dictionaries. The researcher found that there were no differences between printed dictionaries and e-dictionaries concerning word retention and reading comprehension. The researcher justified this result by clarifying that the problem was in students' experience in dealing with e-dictionaries. Of course, this may have been true in 2007 but now as the use of electronic devices has grown enormously all over the world, this will not be a problem for students. Another limitation indicated by the researcher is that the users of e-dictionaries consult their dictionaries more often than the users of printed dictionaries. This could lead to hindering their inferring ability but this was just an assumption that was not supported by evidence.

Darancik (2016) pinpointed that the use of Google Translate can mislead the fresh learners of a foreign language and make them lazier to think about the best translation based on the vocabulary they already know. That is why the researcher emphasized the importance of revising google translations by students.

Most of the studies emphasized the importance of training and the avoidance of overuse of e-dictionaries to 
overcome their limitations. Besides, a number of studies emphasized that e-dictionaries are not effective alone. The present study tries to overcome this limitation through the combining of e-dictionaries with student-created dictionaries.

\section{E. Student-created Dictionaries}

Few studies have covered the issue of student-created dictionaries or learner-constructed glosses. One of these studies is the study of Friedman (2009) who conducted a research project on Japanese university EFL students. The students used the internet and a corpus to study context and features of vocabulary items. Students constructed a dictionary of words and examples. These examples were either taken from the internet or composed by the students themselves. Results of the study revealed that students benefited from this construction of the dictionary as they concentrated on the form, function, and meaning of vocabulary items during the composition process.

Moreover, Fernando and Cooper (2017) reported on the usefulness of some strategies used to support EFL students in learning scientific terminology. They reported that student-created dictionaries can be used both for enhancing proficiency in English as well as a tool for assessing skills. In this strategy, teachers ask learners to construct their own dictionaries using their own definitions. The researchers concluded that this strategy enhances students' creativity. The researchers also emphasized that this strategy will help teachers in their assessment of students' understanding of the terminology incorporated in the glossary.

It is clear that all the above-mentioned studies dealt either with the use of e-dictionaries as a separate tool that can help the improvement of vocabulary acquisition or with student-created dictionaries as strategy for enhancing vocabulary learning. However, the present study combines the use of e-dictionaries with student-created dictionaries. Moreover, most of these studies did not focus on the improvement of pronunciation with the help of e-dictionaries. The present study tries to breach this gap.

\section{RESEARCH QUESTIONS}

1. What is the effect of using e-dictionaries and student-created dictionaries on improving EFL pronunciation?

2. What is the effect of using e-dictionaries and student-created dictionaries on improving EFL vocabulary usage?

3. What are students' perceptions of using e-dictionaries in vocabulary learning?

4. What are students' perceptions of using student-created dictionaries in vocabulary learning?

5. What are students' perceptions of combining e-dictionaries with student-created dictionaries in learning new vocabulary?

\section{RESEARCH HYPOTHESES}

The following hypotheses are related to the first two questions only.

1. There are no significant mean differences at .05 level between the experimental group and the control group on the pronunciation pretest.

2. There are no significant mean differences at .05 level between the experimental group and the control group on the vocabulary usage pretest.

3. There are no significant mean differences at .05 level between the experimental group and the control group on the pronunciation posttest.

4. There are no significant mean differences at .05 level between the experimental group and the control group on the vocabulary usage posttest.

\section{METHOD}

\section{A. Design of the Study}

The study follows a combined quantitative qualitative design. It depends on tests for measuring pronunciation and vocabulary usage in a pretest posttest control group design in order to answer the first two research questions. It also uses combined closed-ended open-ended questionnaires to measure students' perceptions of using e-dictionaries and student-created dictionaries in vocabulary learning in order to answer research questions from three to five. The closedended items provide statistics related to the investigated features while the open-ended items of the questionnaires are presented in a descriptive analytic manner.

\section{B. Participants}

Seventy-three English majors at Jouf University, KSA started this experiment. However, some dropped out and the final number of participants were 62 in the pronunciation posttest and 65 in the vocabulary posttest. The participants voluntarily agreed to participate. The researcher divided the participants into two groups: experimental and control.

\section{The Experimental Group Setting}

Participants in the experimental group studied a listening and speaking course incorporating e-dictionaries and student-created dictionaries. The course consists of six chapters. In each chapter, there are about thirty new vocabulary items. Participants were encouraged to use e-dictionaries to look up these vocabulary items so that they can get the 
meaning and pronunciation. Besides, participants were asked to construct a student-created dictionary by keeping a notebook in which they wrote the new vocabulary items with their meanings followed by an illustrative sentence from their creation.

\section{The Control Group Setting}

Participants in the control group studied the same six chapters with the new vocabulary items. However, they listened to the vocabulary items twice through a tape recorder played inside class and got the meanings of these vocabulary items from the professor teaching the course. Students have different written and spoken activities related to using these vocabulary items.

\section{E. Instruments}

The pronunciation test: The test, in its final form, consists of 20 vocabulary items. The items vary in their difficulty. Students were asked to pronounce the items twice and their pronunciation was recorded.

An analytic rubric was designed to score students' pronunciation. The rubric has four dimensions: consonants, vowels, words with silent letters and multi-syllable words. The scale ranged from 1 to 4 with clear indicator for each category of the scale. A panel of jury established the validity of the test and the rubric. The reliability of the rubric was measured using the inter-rater reliability method. Cronbach's Alpha coefficient was .978.

The vocabulary usage test: The test, in its final form, consists of 30 multiple-choice items. Each item has four alternatives. The 30 items cover a range of vocabulary related to the course of listening and speaking two.

A panel of jury ensured the construct validity of the test. Some modifications related to the items and the alternatives were made based on the jury's comments. The reliability of the test was calculated using Spearman-Brown split half method. Spearman-Brown Coefficient was .675. This reliability coefficient is accepted as coefficients above 60 are generally accepted.

The questionnaire of students' perceptions of using e-dictionaries in vocabulary learning: This questionnaire consists of 20 items; 16 of them are closed-ended items with a four-point Likert-type scale ranging from strongly agree to strongly disagree and 4 of them are open-ended items. The items of the questionnaire covered four dimensions (Table, 1). Item 20 is a general open-ended item not related to any specific dimension.

TABLE (1)

DISTRIBUTION OF THE ITEMS OF THE STUDENTS' PERCEPTIONS QUESTIONNAIRE OF USING E-DICTIONARIES IN VOCABULARY LEARNING

\begin{tabular}{ll}
\hline Dimension & Items \\
\hline Students' willingness to use electronic dictionaries in vocabulary learning & $1-2-3-6-8-9$ \\
Students' perception of the benefits of using electronic dictionaries in vocabulary learning & $4-5-7-17-19$ \\
Students' preferences when using electronic dictionaries in vocabulary learning & $10-11-12-13-14$ \\
Difficulties that face students when using electronic dictionaries in vocabulary learning & $15-16-18$ \\
\hline
\end{tabular}

The panel of jury established the construct validity of the questionnaire. Cronbach's Alpha was used to measure the reliability of the questionnaire and the coefficient was .632. This reliability rate is accepted.

The questionnaire of students' perceptions of using student-created dictionaries in vocabulary learning: This questionnaire consists of 11 items; eight of them are closed-ended items with a four-point Likert-type scale ranging from strongly agree to strongly disagree and three of them are open-ended items. The items of the questionnaire covered four dimensions (Table, 2). Item 11 is a general open-ended item not related to any specific dimension.

TABLE (2)

Distribution Of THE ITEMS Of THE STUDENTS’ PERCEPTIONS QUESTIONNAIRE OF USING STUDENT-CREATED DiCTIONARIES IN VOCABULARY LEARNING

\begin{tabular}{ll}
\hline Dimension & Items \\
\hline Students' willingness to use student-created dictionaries in vocabulary learning & $1-5$ \\
Students' perception of the benefits of using student-created dictionaries in vocabulary learning & $2-3-4-10$ \\
Difficulties that face students when using student-created dictionaries in vocabulary learning & $6-7-9-$ \\
Combining electronic dictionaries with student-created dictionaries in vocabulary learning & 8 \\
\hline
\end{tabular}

The panel of jury established the construct validity of the questionnaire. Cronbach's Alpha was used to measure the reliability of the questionnaire and the coefficient was .641.

\section{F. Statistical Analysis}

The first research hypothesis was tested using t-test for independent samples to determine the equivalence of the experimental and the control groups on the pronunciation pretest (Table, 3).

TABLE (3)

THE T-VAlue For THE PRETEST SCORES OF THE EXPERIMENTAL AND CONTROL GrouPs ON PRONUNCIATION

\begin{tabular}{lcccc}
\multicolumn{2}{c}{ THE T-VALUE FOR THE PRETEST SCORES OF THE EXPERIMENTAL AND CONTROL GROUPS ON PRONUNCIATION } \\
\hline Group & $\mathrm{N}$ & Mean & Std. Deviation & t-value \\
& & & & $\begin{array}{l}\text { Sig. } \\
(2-\text { tailed })\end{array}$ \\
\hline Experimental & 40 & 7.17 & 2.8 & 0.165 \\
Control & 32 & 8.06 & 2.47 & 0.103 \\
\hline
\end{tabular}


The t-test results show that no statistically significant differences were found between the pretest mean scores of the experimental and control groups on pronunciation $(p>0.05)$. Thus, the hypothesis is accepted. This indicates that the two groups are equivalent and thus the study will use t-test for independent samples to compare posttest scores.

The second research hypothesis was tested using t-test for independent samples to determine the equivalence of the experimental and the control groups on the vocabulary usage pretest (Table, 4).

TABLE (4)

\begin{tabular}{lcccc}
\multicolumn{2}{c}{ THE T-VALUE FOR THE PRETEST SCORES OF THE EXPERIMENTAL AND CONTROL GROUPS ON VOCABULARY USAGE } \\
\hline Group & $\mathrm{N}$ & Mean & Std. Deviation & $\begin{array}{c}\text { t-value } \\
(2-\text { tailed) }\end{array}$ \\
\hline Experimental & & & & 0.193 \\
Control & 44 & 14.03 & 5.29 & 0.847 \\
\hline
\end{tabular}

The t-test results show that no statistically significant differences were found between the pretest mean scores of the experimental and control groups on vocabulary usage ( $>>0.05)$. Thus, the hypothesis is accepted. This indicates that the two groups are equivalent and thus the study will use t-test for independent samples to compare posttest scores.

For statistical analysis of the closed-ended items of the questionnaire, the researcher depended on frequencies. As for the open-ended items, the researcher depended on descriptive analytic presentation.

\section{RESULTS}

\section{A. The Impact of E-dictionaries and Student-created Dictionaries on Students' Pronunciation}

T-test for independent groups was applied to test the related hypothesis (hypothesis three). Table (5) shows the results.

TABLE (5)

T-TEST FOR INDEPENDENT GROUPS OF THE IMPACT OF ELECTRONIC AND STUDENT-CREATED DICTIONARIES ON PRONUNCIATION

\begin{tabular}{llllll}
\hline Group & $\mathrm{N}$ & Mean & Std. Deviation & t-value & Sig. (2-tailed) \\
\hline Experimental & 33 & 24.87 & 3.63 & -3.26 & 0.001 \\
Control & 29 & 20.79 & 6.04 & & \\
\hline
\end{tabular}

From the table it is clear that the experimental group outperformed the control group in the posttest of pronunciation ( $\mathrm{p}<0.05$ ). Thus, the use of electronic and student-created dictionaries proved to be effective in enhancing students' pronunciation.

\section{B. The Impact of E-dictionaries and Student-created Dictionaries on Students' Vocabulary Usage}

T-test for independent groups was applied to test the related hypothesis (hypothesis four). Table (6) shows the results.

TABLE (6)

\begin{tabular}{llllll} 
T-TEST FOR INDEPENDENT GROUPS OF THE IMPACT OF ELECTRONIC AND STUDENT-CREATED DiCTIONARIES ON VOCABULARY \\
\hline Group & $\mathrm{N}$ & Mean & Std. Deviation & t-value & Sig.(2-tailed) \\
\hline Experimental & 34 & 12.61 & 1.85 & -8.11 & 0.000 \\
Control & 31 & 8.09 & 2.59 & & \\
\hline
\end{tabular}

From the table it is clear that the experimental group outperformed the control group in the posttest of vocabulary ( $\mathrm{p}<$ 0.05). Thus, the use of electronic and student-created dictionaries proved to be effective in enhancing students' vocabulary usage.

\section{Students' Perceptions of Using E-dictionaries in Vocabulary Learning}

The first dimension of the questionnaire, students' willingness to use e- dictionaries in vocabulary learning, consists of six items. Table (7) clarifies the frequencies of each item.

TABLE (7)

FREQUENCIES OF STUDENTS' WILLINGNESS TO USE E-DICTIONARIES IN VOCABULARY LEARNING

\begin{tabular}{|c|c|c|c|c|}
\hline Item & $\begin{array}{l}\text { Strongly } \\
\text { Agree }\end{array}$ & Agree & Disagree & Strongly disagree \\
\hline $\begin{array}{l}\text { 1. I prefer to look up the new words on an electronic dictionary not a paper } \\
\text { dictionary. }\end{array}$ & 75 & 20.5 & 0 & 4.5 \\
\hline $\begin{array}{l}\text { 2. I prefer to listen to the pronunciation of new words on electronic } \\
\text { dictionaries than from my tutor. }\end{array}$ & 34.1 & 27.3 & 29.5 & 9.1 \\
\hline 3. I use the electronic dictionaries only because my tutor asked me. & 13.6 & 9.1 & 22.7 & 54.5 \\
\hline 6. I am good at using electronic dictionaries & 72.7 & 22.7 & 2.3 & 2.3 \\
\hline 8. I like using electronic dictionaries in class. & 45.5 & 40.9 & 9.1 & 4.5 \\
\hline 9. I like using electronic dictionaries at home. & 56.8 & 31.8 & 4.5 & 6.8 \\
\hline
\end{tabular}


It is clear from the table that the majority of students were willing to use e-dictionaries in vocabulary learning. Preferring e-dictionaries to paper dictionaries got $95.5 \%$ agreement (75\% strongly agree and $20.5 \%$ agree). Feeling competent of using e-dictionaries follows with $95.4 \%$ agreement. Willingness to use e-dictionaries at home follows with $88.6 \%$ agreement. Willingness to use e-dictionaries in class follows with $86.4 \%$ agreement. Preferring getting pronunciation from e-dictionaries follows with $61.4 \%$ agreement. Finally, only $22.7 \%$ of the participants stated that they used e-dictionaries only because the tutor asked them. This means they are willing to use it for its benefits not because it is a requirement by the tutor.

The second dimension of the questionnaire, students' perceptions of the benefits of using e-dictionaries in vocabulary learning, consists of five items. Three of them are closed-ended, one multiple-choice and one open-ended item. Table (8) clarifies the frequencies of the closed-ended items.

TABLE (8)

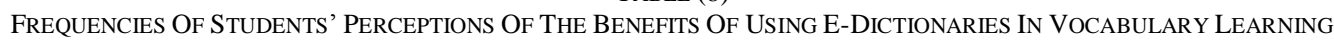

\begin{tabular}{|c|c|c|c|c|}
\hline Item & Strongly Agree & Agree & Disagree & Strongly disagree \\
\hline $\begin{array}{l}\text { 4. I use electronic dictionaries because it provides clear meaning of the } \\
\text { new words easily. }\end{array}$ & 68.2 & 20.5 & 11.4 & 0 \\
\hline $\begin{array}{l}\text { 5. I use electronic dictionaries because it provides clear pronunciation of } \\
\text { the new words easily. }\end{array}$ & 52.3 & 38.6 & 9.1 & 0 \\
\hline 7. Looking up the new words in electronic dictionaries saves time. & 75 & 15.9 & 6.8 & 2.3 \\
\hline
\end{tabular}

It is clear from the table that the highest perceived benefit of e-dictionaries is getting clear pronunciation of the word easily as this item got $90.9 \%$ agreement. Saving time got the same percent of agreement $90.9 \%$. Getting a clear meaning of the word easily follows with $88.7 \%$.

The multiple-choice item (item 17) gave students four possible benefits to choose the most important for them. Analysis of participants' responses shows that speed came on top of the benefits with $34.1 \%$. Correct pronunciation follows with $31.8 \%$. Ease of use follows with $27.3 \%$. Finally, accurate Arabic translation got $6.8 \%$, which is a low percent.

The open-ended item (item 19) asked students to write any benefit of the use of e-dictionaries. Analysis of participants' responses resulted in the following list of benefits ordered according to frequency:

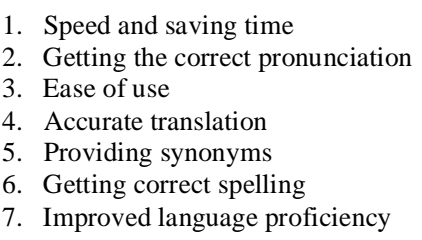

8. Improved use of vocabulary.

9. Memorizing vocabulary

10. Revising vocabulary

11. E-dictionaries can be used anywhere

12. Providing the part of speech

13. Some e-dictionaries have a photocopy and translate option

It is very clear that the top four items in the list are consistent with participants' responses to the three closed-ended items in table (8). As can be seen in the list participants added other valuable benefits of using e-dictionaries.

The third dimension of the questionnaire, students' preferences when using e-dictionaries in vocabulary learning, consists of five items. Table (9) clarifies the frequencies of each item.

TABLE (9)

FREQUENCIES OF STUDENTS' PREFERENCES WHEN USING E-DiCTIONARIES IN VOCABULARY LEARNING

\begin{tabular}{|c|c|c|c|c|}
\hline Item & $\begin{array}{l}\text { Strongly } \\
\text { Agree }\end{array}$ & Agree & Disagree & $\begin{array}{l}\text { Strongly } \\
\text { disagree }\end{array}$ \\
\hline 10. I only use google translate not any other electronic dictionary. & 13.6 & 20.5 & 29.5 & 36.4 \\
\hline 11. I use different electronic dictionaries. & 34.1 & 34.1 & 22.7 & 9.1 \\
\hline $\begin{array}{l}\text { 12. I prefer English - Arabic electronic dictionaries than English - } \\
\text { English ones. }\end{array}$ & 29.5 & 50 & 11.4 & 9.1 \\
\hline $\begin{array}{l}\text { 13. I listen to the word on electronic dictionaries more than once to } \\
\text { master its pronunciation. }\end{array}$ & 59.1 & 27.3 & 6.8 & 6.8 \\
\hline $\begin{array}{l}\text { 14. I repeat after the speaker when I listen to the pronunciation of } \\
\text { the word on electronic dictionaries. }\end{array}$ & 38.6 & 40.9 & 15.9 & 4.5 \\
\hline
\end{tabular}

It is clear from the table (item 13) that $86.4 \%$ of the participants prefer to listen to the word on e-dictionaries more than once to get its correct pronunciation. Analysis of item 12 shows that $79.5 \%$ of the participants prefer EnglishArabic e-dictionaries over English-English ones. Analysis of item 14 shows that $79.5 \%$ of the participants prefer to repeat after the speaker of e-dictionaries when they listen to new words. Analysis of item 11 shows that $68.2 \%$ of the 
participants use a variety of e-dictionaries. Analysis of item 10 verifies the same result as only $34.1 \%$ declared that they only use Google Translate.

The fourth dimension of the questionnaire, difficulties that face students when using e-dictionaries in vocabulary learning, consists of two closed-ended items and one open-ended item. Table (10) clarifies the frequencies of closedended items.

TABLE (10)

FREQUENCIES OF DifFicUlties THAT FACE STUDENTS WHEN USING E-DiCTIONARIES IN VOCABULARY LEARNING

\begin{tabular}{|c|c|c|c|c|}
\hline Item & Strongly Agree & Agree & Disagree & $\begin{array}{l}\text { Strongly } \\
\text { disagree }\end{array}$ \\
\hline $\begin{array}{l}\text { 15. I can't find the meaning of some words on electronic } \\
\text { dictionaries }\end{array}$ & 9.1 & 47.7 & 22.7 & 20.5 \\
\hline $\begin{array}{l}\text { 16. It takes a lot of time to find the meaning and } \\
\text { pronunciation of all new words in each chapter using } \\
\text { electronic dictionaries. }\end{array}$ & 27.3 & 31.8 & 22.7 & 18.2 \\
\hline
\end{tabular}

It is clear from the table (item 16) that $59.1 \%$ of participants find it time-consuming to find the meaning of all new words using e-dictionaries. Analysis of item 15 shows that 56.8 of the participants sometimes cannot get the meaning of some words using e-dictionaries.

Item 18 was an open-ended item asking students to list any difficulty they have faced during the use of e-dictionaries. Analysis of participants' responses resulted in the following list ordered according to frequency:

1. Inaccurate translation

2. Inability to find the meaning of some words especially idioms, reduced words, and phrasal verbs.

3. E-dictionaries provide more than one meaning which could be confusing
4. Technical problems with the internet access. Inaccurate pronunciation.

5. Low unclear sound of pronunciation.

6. Technical problems related to the lack of training

7. Preferring teacher translation because of time pressure.

Time pressure came last in students list though about $60 \%$ reported it as a problem in item 16 . This means participants feel that there are other more important problems of using e-dictionaries such as inaccurate translations and inability to find meanings of some idioms, which goes along with their responses to item 15 .

Item 20 was an additional item not related to any specific dimension of the questionnaire. It gave participants the opportunity to express their remarks and suggestions about the use of e-dictionaries. Analysis of participants' responses resulted in the following list of suggestions ordered according to frequency:

1. It is better to use e-dictionaries in class

2. To be used in all courses

3. To be used at home.

4. Students' discussion over the meaning of words

5. Use English-English apps.
6. To have a separate course for vocabulary and use it.

7. To be carried out in groups

8. To select one type of e-dictionaries for all students to use

9. Use e-dictionaries not online apps.

\section{Students' Perceptions of Using Student-created Dictionaries and Combining them with E-dictionaries in Vocabulary} Learning

The first dimension of the questionnaire, students' willingness to use student-created dictionaries in vocabulary learning, consists of two items. Table (11) clarifies the frequencies of each item.

TABLE (11)

FREQUENCIES OF STUDENTS' WILLINGNESS TO USE STUDENT-CREATED DiCTIONARIES IN VocABULARY LEARNING

\begin{tabular}{|c|c|c|c|c|}
\hline Item & $\begin{array}{l}\text { Strongly } \\
\text { Agree }\end{array}$ & Agree & Disagree & $\begin{array}{l}\text { Strongly } \\
\text { disagree }\end{array}$ \\
\hline $\begin{array}{l}\text { 1. I created my own dictionary only because my tutor asked } \\
\text { me. }\end{array}$ & 18.2 & 31.8 & 25 & 25 \\
\hline 5. Creating my own dictionary makes me proud. & 47.7 & 40.9 & 4.5 & 8.6 \\
\hline
\end{tabular}

It is clear from the table that the majority of the participants were willing to use student-created dictionaries in vocabulary learning. Analysis of item 5 shows that $88.6 \%$ of the participants felt proud of creating their own dictionaries, which gives clear indication that they are willing to use this technique. This goes along with the result of item 1 , which shows that $50 \%$ did it because the teacher asked them while the other $50 \%$ of participants did it for other reasons. This indicates intrinsic willingness to construct student-created dictionaries in at least $50 \%$ of the students.

The second dimension of the questionnaire, students' perceptions of the benefits of using student-created dictionaries in vocabulary learning, consists of three closed-ended items and one open-ended item. Table (12) clarifies the frequencies of closed-ended items. 
TABLE (12)

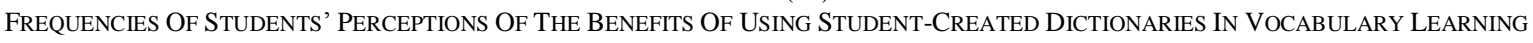

\begin{tabular}{llccc}
\hline Item & Strongly Agree & Agree & Disagree & $\begin{array}{c}\text { Strongly } \\
\text { disagree }\end{array}$ \\
\hline $\begin{array}{l}\text { 2. I created my own dictionary because it helps me revise } \\
\text { the new words easily. }\end{array}$ & 54.5 & 25 & 13.6 & 6.8 \\
$\begin{array}{l}\text { 3. I created my own dictionary because it enables me to } \\
\text { use the new word in a sentence. }\end{array}$ & 38.6 & 45.5 & 6.8 & 9.1 \\
$\begin{array}{l}\text { 4. Creating my own dictionary helped me remember the } \\
\text { new words for a long time. }\end{array}$ & 54.5 & 36.4 & 4.5 & 4.5 \\
\hline
\end{tabular}

It is clear from the analysis of item 4 that $90.9 \%$ of the participants perceived that the most important benefit of using student-created dictionaries in vocabulary learning is the long retention of learned vocabulary. Using the new word in a sentence came second as declared in item 3 with a percentage of $83.1 \%$. Revising vocabulary came third with $79.5 \%$ as stated in item 2.

Item 10 was an open-ended item asking students to list all the perceived benefits of student-created dictionaries. Analysis of students' responses resulted in the following list of benefits ordered according to their frequency:
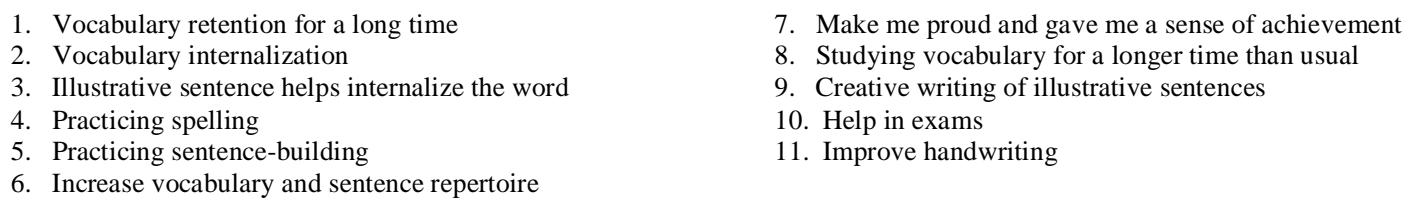

It is clear that this list is consistent with the results of the closed-ended items. The first two items in this list are the same as the highest two closed-ended items. Participants added other valuable benefits of using student-created dictionaries, which indicates their high appreciation of the technique.

6.4.3. The third dimension of the questionnaire, difficulties that face students when using student-created dictionaries in vocabulary learning, consists of two closed-ended items and one open-ended item. Table (13) clarifies the frequencies of closed-ended items.

TABLE (13)

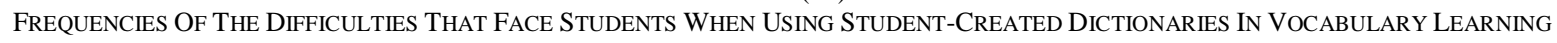

\begin{tabular}{|c|c|c|c|c|}
\hline Item & $\begin{array}{l}\text { Strongly } \\
\text { Agree }\end{array}$ & Agree & Disagree & Strongly disagree \\
\hline $\begin{array}{l}\text { 6. Writing a sentence illustrating the meaning of each word was } \\
\text { difficult. }\end{array}$ & 15.9 & 31.8 & 31.8 & 20.5 \\
\hline 7. Keeping the student-created dictionary was exhausting. & 20.5 & 29.5 & 34.1 & 15.9 \\
\hline
\end{tabular}

It is clear from the analysis of item 7 that $50 \%$ of the participants found it exhausting to keep a student-created dictionary. $47.7 \%$ of the participants declared that writing the illustrative sentence was difficult.

Item 9 was an open-ended item asking students to list all the perceived difficulties of building student-created dictionaries. Analysis of students' responses resulted in the following list ordered according to their frequency:
1. Writing a suitable illustrative sentence
2. Time consuming
5. Translating idioms into Arabic
3. Hard work as there are a lot of words to include
6. Needs training
7. Being lazy
4. Difficulty of some vocabulary items
8. Writing already known words.

It is clear that this list is consistent with the results of the closed-ended items. Participants added other difficulties of using student-created dictionaries.

The fourth dimension of the questionnaire, combining e-dictionaries with student-created dictionaries in vocabulary learning, is covered by one item. Table (14) clarifies the frequencies of this item.

TABLE (14)

FREQUENCIES OF STUdENTS' PERCEPTIONS OF COMBINING ELECTRONIC DiCTIONARIES WiTH STUDENT-CREATED DiCTIONARIES IN VOCABULARY

\begin{tabular}{llll} 
& LEARNING & & \\
\hline Item & $\begin{array}{l}\text { Strongly } \\
\text { Agree }\end{array}$ & Agree & $\begin{array}{c}\text { Disagree } \\
\text { disagree }\end{array}$ \\
\hline $\begin{array}{l}\text { 8. Using electronic dictionaries combined with student-created } \\
\text { dictionaries helped me a lot in learning new words. }\end{array}$ & 61.4 & 29.5 & 9.1 \\
\end{tabular}

Analysis of item (8) shows that $90.9 \%$ of the participants find combing e-dictionaries with student-created dictionaries beneficial. This means the majority are in favor of this combination.

Item 11 is an open-ended item that is not related to any specific dimension. Analysis of this item resulted in the following list of suggestions ordered according to their frequency: 
1. It is better to be done in class

2. To be used with important words only not all new words

3 . To be used in other courses especially reading and writing

4. To be checked more often

5. To be optional

6. Teacher makes illustrative sentence

7. No illustrative sentence.
8. Cooperative work to construct the dictionary

9. To use teacher definition instead of dictionary definition

10. Type it instead of handwriting

11. Students present the words every class

12. Write a definition before the illustrative sentence.

\section{DISCUSSION}

Based on the results presented, the use of e-dictionaries and student-created dictionaries improved participants' pronunciation of vocabulary. This could be because through e-dictionaries participants could listen to the new vocabulary items many times. The participants in the questionnaire measuring their perceptions of using e-dictionaries reported doing this. In addition, it could be because most participants repeated the word after the speaker of the edictionary. This repetition helped them master the pronunciation of the new vocabulary items.

Moreover, e-dictionaries combined with student-created dictionaries enhanced participants use of vocabulary. This supports results found by Fageeh, 2014; Nisbet and Austin, 2013; Wang, 2012 and Loucky, 2010 who found positive effects of using e-dictionaries on vocabulary usage. This also supports the results of Friedman, 2009 who found out that student-created dictionaries were effective in vocabulary enhancement. On the other hand, some previous studies do not support this as Chiu and Liu, 2013 who found out that printed dictionaries are more effective regarding vocabulary retention. In addition, Kobayashi, 2007 found out that there is no difference between printed and e-dictionaries. One more thing is that previous studies focused on one type of dictionaries while the present study provided evidence that the combination of both e-dictionaries and student-created dictionaries proved to be effective for enhancing both pronunciation and vocabulary usage.

Students' perceptions of using e-dictionaries in vocabulary learning are generally positive. The majority of the participants were willing to use e-dictionaries. This supports results found by Fageeh, 2014; Nisbet and Austin, 2013; Loucky, 2010 and Lenders, 2008. One of the top benefits of e-dictionaries as reported by participants is speed of getting the meaning of new words. This goes along with the results obtained by Chen, 2010 and Loucky, 2002. Another benefit that agrees with previous studies is consolidating words, which was mentioned by participants in the open-ended item as memorizing and revising vocabulary. This agrees with Dilenschneider, 2018. However, unlike previous studies, the present study found out that the majority of participants declared that getting the correct pronunciation quickly is one of the top benefits of using e-dictionaries. The present study found out some more advantages of e-dictionaries such as the ease of use and the availability of using e-dictionaries everywhere. Some of the difficulties found by the present study supports previous studies such as problems of collocations and idioms which agrees with the study of Niitemaa and Pietilä , 2018; and problems with accuracy of meaning obtained from e-dictionaries which agrees with the study of Dalton and Grisham, 2011. The present study pinpointed some difficulties that were not mentioned earlier such as the confusion caused by different meanings provided and the technical problems. One unexpected problem was reported by participants is the inaccurate pronunciation. This could be due to students' inability to judge the correct pronunciation or due to the poor quality of the sound of the application, which could result in students' mishearing of the pronunciation. As for students' suggestions related to the use of e-dictionaries, one suggestion that this study shares with the study of Bower and McMillan, 2007 is the need for training. One important suggestion, which came second in frequency, is related to the use of e-dictionaries in all courses. This indicates strong willingness to use e-dictionaries. A suggestion that brought a new idea that could be applied is the collaborative use of e-dictionaries instead of individualized use.

Students' perceptions of using student-created dictionaries in vocabulary learning are generally positive. Students were willing to use student-created dictionaries. Student reported many benefits for using student-created dictionaries. One of the benefits that the present study shares with the study of Fernando and Cooper, 2017 is enhancing creativity. The creativity is enhanced through the construction of illustrative sentences. Two new benefits of student-created dictionaries are long vocabulary retention and internalizing vocabulary through illustrative sentences. However, time consumption and difficulty of creating illustrative sentences were big problems for students. This could be due to two factors. First, students are not used to writing a lot and their level of writing is low. Second, the research observed that students' created sentences where not typical illustrative sentences. Many sentences were very simple and not expressive enough of the meaning of the word. As for students' suggestions for the use of student-created dictionaries, they emphasize students' willingness to use this technique as they suggest using it in other courses. It also highlights the difficulties found out above. The emphasis on collaboration again appears as students suggested that student-created dictionaries could be created collaboratively. This indicates that students prefer cooperative work to individual work.

The majority of the participants were in favor of combining e-dictionaries with student-created dictionaries. This agrees with the study of Poole, 2012 who found out that e-dictionaries alone are not enough and called for combining it with other tools to maximize its benefit. In his case, he combined it with corpus. However, from field observations during the experiment, the research found out that students focused on student-created dictionaries more than edictionaries. They focused on the meaning of the word more than its pronunciation. This may be due to their previous conceptions that the most important thing is the meaning of the word not its pronunciation. 
It is clear that there is strong consistency between what students wrote in the open-ended items of the two questionnaires with their responses in the closed ended items in all dimensions. This adds to the reliability of the results of the questionnaires.

\section{CONCLUSION AND RECOMMENDATIONS}

The study found out that the usage of electronic and student-created dictionaries improved students' pronunciation as well as their vocabulary usage abilities. Results also revealed that participants are willing to use both electronic and student-created dictionaries in vocabulary learning. The most frequent perceived benefits of electronic dictionaries are the speed of accessing the meaning of new vocabulary items and getting clear correct pronunciation of them. The most frequent perceived benefits of student-created dictionaries are long retention of new vocabulary and internalizing them through illustrative sentences. Participants face some challenges when using electronic dictionaries such as the inability to find accurate meaning of some vocabulary items and some technical problems related to internet access and lack of sufficient training. Participants face some problems with their student-created dictionaries such as difficulty in constructing illustrative sentences and time-consumption.

Theoretically, this study breached a research gap as it combined e-dictionaries with student-created dictionaries. This was not done by any previous study. In addition, the study focused on effects of e-dictionaries on pronunciation development, which was, also neglected by previous studies.

Practically, the study gives clear insight on the use of e-dictionaries and student-created dictionaries. This could help language learners and language instructors in different levels to develop the process of vocabulary learning. The study also gives recommendations to designers of e-dictionaries to enhance their products. The study could help curriculum designers to add e-dictionaries and student-created dictionaries as one of the suggested methods for teaching and learning vocabulary.

Based on the results, the study recommends the incorporation of e-dictionaries and student-created dictionaries in the EFL learning of vocabulary. The study also suggests that these two techniques should be used both in-class and out of class. The study recommends sufficient training to students and tutors before the use of both techniques. The study also, recommends that the two techniques should be used as cooperative activities not individual activities. The study recommends that e-dictionary designers raise the volume of pronunciation and try incorporating more idioms in the dictionaries. Further studies are needed to investigate the potentials of both techniques in different settings.

\section{ACKNOWLEDGEMENTS}

This research was funded by Jouf University. Grant no. (244/39).

Greatest gratitude to the panel of jury, professors: Atallah Alsardi, Hammad Alshamari, and Elsayed Abdullah, who reviewed and helped in validating the research tools.

\section{REFERENCES}

[1] Abraham, L. (2008). Computer-mediated glosses in second language reading comprehension and vocabulary learning: A metaanalysis, Computer Assisted Language Learning, 21(3), 199-226,DOI: 10.1080/09588220802090246.

[2] Bahri, H. \& Mahadi, T. (2016). Google translate as a supplementary tool for learning Malay: A case study at university Sains Malaysia. Advances in Language and Literary Studies, 7(3):161-167.

[3] Bower, J., \& McMillan, B. (2007). Learner use and views of portable electronic dictionaries. In K. Bradford-Watts (Ed.), JALT2006 Conference Proceedings. Tokyo: JALT.

[4] Chen, Y. (2010). Dictionary use and EFL learning. A contrastive study of pocket electronic dictionaries and paper dictionari es, International Journal of Lexicography, 23 (3), 275-306, https://doi-org.sdl.idm.oclc.org/10.1093/ijl/ecq013.

[5] Chiu, L. \& Liu, G. (2013). Effects of printed, pocket electronic and online dictionaries on high school students' English vocabulary retention, Asia-Pacific Education Researcher 22(4):619-634. DOI 10.1007/s40299-013-0065-1.

[6] Darancik, Y. (2016). The effect of data-based translation program used in foreign language education on the correct use of language. TOJET: The Turkish Online Journal of Educational Technology,15 (4), 88-106.

[7] Dalton, B. \& Grisham, D. (2011). eVoc strategies: 10 ways to use technology to build vocabulary. The Reading Teacher, 64(5), 306-317.

[8] Dilenschneider, R. (2018). Examining the conditions of using an on-line dictionary to learn words and comprehend texts. ReCALL, 30(1), 4-23. doi:10.1017/S0958344017000234.

[9] Fageeh, A. I. (2014). Effects of using the online dictionary for etymological analysis on vocabulary development in EFL college students. Theory and Practice in Language Studies, 4(5), 883-890.

[10] Fernando, P \& Cooper, R. (2017). Supporting EAL students in learning biology terminology. Teaching Science: The Journal of the Australian Science Teachers Association, 63 (1), 34-40

[11] Friedman, G. (2009). Learner-created lexical databases using web-based source material, ELT Journal, 63 (2),126-136, https://doi-org.sdl.idm.oclc.org/10.1093/elt/ccn022.

[12] Kobayashi, C. (2007). Comparing electronic and printed dictionaries: Their effects on lexical processing strategy use, word retention, and reading comprehension. In K. Bradford-Watts (Ed.), JALT2006 Conference Proceedings. Tokyo: JALT.

[13] Lenders, O. (2008). Electronic glossing: Is it worth the effort? Computer Assisted Language Learning, 21, 457-481. 
[14] Loucky, J. (2002). Comparing translation software and OCR reading pens. In M. Swanson, C. McMurray, \& K. Lane (Eds.), Pan-Asian Conference 3 at 27th International Conference of JALT National Conference Proceedings CD (pp. 745-755). Kitakyushu, Japan.

[15] Loucky, J. (2005) Combining the benefits of electronic and online dictionaries with CALL web sites to produce effective and enjoyable vocabulary and language learning lessons, Computer Assisted Language Learning, 18(5), 389-416, DOI: $10.1080 / 09588220500442764$.

[16] Loucky, J. (2010). Comparing electronic dictionary: Functions and use, CALICO Journal, 28(1), 156-174.

[17] Niitemaa, M. \& Pietilä, P. (2018)Vocabulary skills and online dictionaries: A study on EFL learners' receptive vocabulary knowledge and success in searching electronic sources for information, Journal of Language Teaching and Research. 9(3), 453-462, DOI: http://dx.doi.org/10.17507/jltr.0903.02.

[18] Nisbet, D. \& Austin, D. (2013). Enhancing ESL vocabulary development through the use of mobile technology. Journal of Adult Education, 42(1), 1-7.

[19] Poole, R. (2012). Concordance-based glosses for academic vocabulary acquisitions, CALICO, 29 (4), 679-693. DOI: $10.11139 /$ cj.29.4.679-693.

[20] Wang, J. (2012).The use of e-dictionary to read e-text by intermediate and advanced learners of Chinese, Computer Assisted Language Learning, 25 (5), 475-487.

Hosam ELDeen A. El-Sawy, PhD in TESOL, Alexandria University, Egypt, 2010. Master in TESOL, Alexandria University, Egypt, 2005.

He worked as a Teaching Assistant, an Assistant Lecturer and a Lecturer at Alexandria and Damnahour Universities, Egypt. He currently works as an Assistant Professor at Jouf University, KSA. He has published work in using social network sites in teaching English, using picture storybooks in teaching EFL reading skills, authentic tasks for improving EFL speaking skills, flipping EFL university classes and relevance among EFL teacher preparation courses and their teaching behaviors and views. Authenticity and using technology in language teaching are his current research interests. 